\title{
Membros Legendários da SOBER - 2004
}

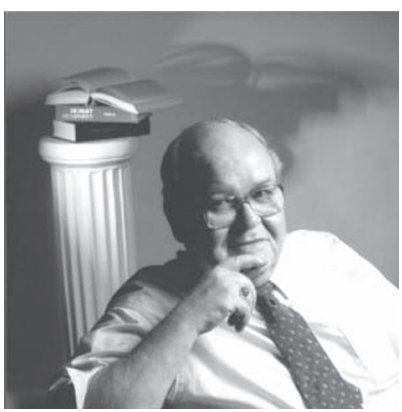

G. Edward Schuh
Edward Schuh nasceu aos 19 de setembro • de 1930, nos Estados Unidos da América. Graduou-se Bacharel em Economia Agrícola pela Purdue University. Concluiu o mestrado na Michigan State University e obteve o título de PhD na University of Chicago.

De 1959 a 1979, foi professor de Economia Agrícola da Purdue University; professor no Convênio Universidade Federal de Viçosa/Purdue University, em Minas Gerais, onde colaborou na implantação do Programa de Pós-Graduação em Economia Rural da UFV, curso pioneiro no Brasil. Nos anos setenta, foi Diretor do Programa de Agricultura do Brasil e da América Latina da Fundação Ford, no Rio de Janeiro. E, posteriormente, desempenhou as funções Membro do Council of Economic Advisors na administração do Presidente Gerald Ford, em Washington, D.C.

Entre 1979 e 1984, chefiou o Departamento de Economia Agrícola e Aplicada da University of Minnesota. Em 1985, tornou-se Vice-Ministro do United States Department of Agiculture - USDA em Washington, D.C. No ano seguinte, foi Diretor de Desenvolvimento Agrícola e Rural do Banco Mundial, permanecendo no cargo até 1989, quando passou a chefiar o Humphrey Institute of Public Affairs and Planning, em Minnesota, USA. Desde 1997, possui o título de Freeman Chair Professor pela University of Minnesota, onde continua ensinando e pesquisando.

Ademais, acumulou durante sua vida os tí- 
tulos de Fellow e Ex-Presidente da Associação Americana de Economia Agrícola (AAEA), Professor Honoris Causa da Universidade Federal de Viçosa, Doutor Honoris Causa pela Purdue University e Fellow da Academia Americana de Artes e Ciência e também da Associação Americana para o Avanço da Ciência. Recebeu cinco prêmios da AAEA, além de presidir a mesma.

Até hoje, Ed Schuh publicou seis livros sobre Desenvolvimento Agrícola e Políticas Públicas e mais de 150 artigos e relatórios de pesquisa. Orientou mais de 100 alunos de mestrado e doutorado, dentre os quais, mais de 40 são brasileiros.

Na vida acadêmica, sempre priorizou o investimento em capital humano nos países em desenvolvimento, particularmente nos países da América Latina e África. Valorizou também a importância do comércio internacional e das políticas gerais de desenvolvimento econômico. 


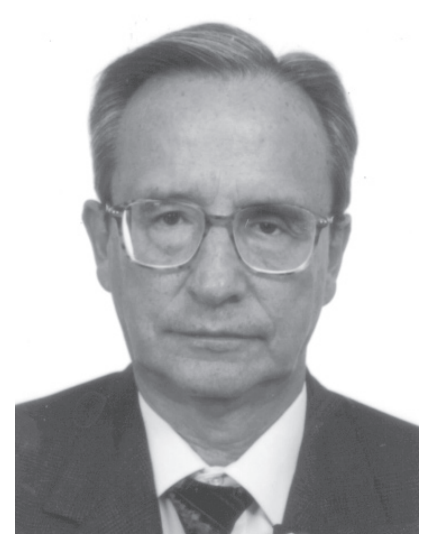

Eliseu Roberto de Andrade Alves
$\mathbf{V}_{\text {ves atuou como extensionista, pesquisador, }}^{\text {os } 50 \text { anos de vida profissional, Eliseu Al- }}$ professor visitante (EPGE da FGV, pós-graduação em economia da USP, CEDEPLAR da Universidade Federal de Minas Gerais), administrador e publicou mais de dois artigos por ano. Lutou para aumentar os recursos da extensão rural, Embrapa, Companhia de Desenvolvimento do Vale São Francisco (Codevasf) e pela consolidação da Sociedade Brasileira de Economia e Sociologia Rural (SOBER).

Atuou exclusivamente na extensão rural (ACAR - MG), de 1955 a 1972, ajudando a consolidar o modelo. Publicou muitos trabalhos para mostrar o seu impacto. No período de 1971 a 1972, fez parte do grupo de trabalho criado por Aloísio Campelo, da ABCAR, por sugestão de Renato Simplício Lopes da ACAR. Uma questão que o grupo devia responder era por que, a despeito de regada a crédito subsidiado e de dispor de um bom serviço de extensão rural, a produtividade da agricultura estava estagnada ou pouco crescia. Liderado por José Pastore, o grupo debateu a questão, fez pesquisa de campo e chegou à conclusão que o entrave maior era falta de resultados de pesquisa. Conclusões semelhantes se verificaram em muitos países, em parte por influência de T. W. Schultz, da Universidade de Chicago e de Vernon Ruttan, da Universidade de Minnessota. Então, nasceu a idéia de reformular o serviço de pesquisa do Ministério de Agricultura, DNPEA. A idéia foi proposta ao ministro Cirne Lima, e por ele aceita, com entusiasmo. Em 26 de abril de 1973, a Embrapa foi instalada, sendo seu presidente José Irineu Cabral.

De 1973 a 1979, fez parte da primeira dire- 
toria do Programa de Recursos Humanos, Métodos Quantitativos e Difusão de Tecnologia. Ajudou a conceber, em 1974, o modelo organizacional da Embrapa, baseado nos centros nacionais. A idéia estava presente na ACAR, à época em que se debatia a dispersão de esforços e se procurava meios para concentrar os recursos. Os centros nacionais são uma resposta à dispersão de esforços, no âmbito da pesquisa.

Em 1979, Eliseu Alves tornou-se presidente da Embrapa. De 1973 a 1985, mais de dois mil cientistas completaram o mestrado e doutorado, no Brasil e no exterior. Esforço de igual tamanho, em tão curto período, não foi feito por nenhum país. O BID, o BIRD, vários países, como os Estados Unidos, França e Japão, tiveram e têm papel importante nesta grande aventura que é a Embrapa.

Em 1985, tornou-se presidente da Codevasf, cargo que exerceu até 1990. Ajudou a comandar o Programa de Um Milhão de Hectares Irrigados, do presidente Sarney. Na Codevasf, dedicou-se a captar recursos externos (BID, BIRD, Japão e Hungria) e recursos internos, deixando recursos para os dez anos seguintes. Implantou novos projetos, entregou a administração de todos os projetos aos agricultores, emancipando-os e ajudou a estabelecer as bases de uma política expressiva de exportação de frutas e hortaliças in natura, hoje um grande sucesso.

Eliseu Alves continuou como pesquisador durante os 17 anos em que foi diretor ou presidente. Lecionou neste período, orientou estudantes, participou dos boards dos centros internacionais de pesquisa, como IFPRI, CIAT, ICRISAT e IIMI, participou do Conselho Nacional de Ciência e Tecnologia do CNPQ e do Ministério de Ciência e Tecnologia.

Desde 1973, tem participado ativamente da discussão da política agrícola, mormente na área de ciência e tecnologia, Nordeste, leite e pobreza rural.

Em 1990, optou exclusivamente pela pesquisa, nas seguintes áreas: Agronegócio, Irrigação, Pobreza Rural, Ciência e Tecnologia e Política Agrícola.

Ajudou a estabelecer o modelo do SENAR, sob o comando da CNA. Em seus 50 anos de profissão, foi sempre servidor público com dois patrões, apenas: a ACAR e a Embrapa. Passou três anos no exterior, para concluir seu mestrado e seu PHD, em Economia Rural, na Universidade de Purdue. De resto, sua luta tem sido toda no Brasil. Prestou consultorias ao Banco Mundial (BIRD), Banco Interamericano de Desenvolvimento (BID), FAO e IICA, sempre em assuntos relacionados à pesquisa ou à irrigação.

Recebeu algumas distinções e honrarias especiais, dentre elas: Medalha 
do Mérito Universitário da Universidade Federal de Pelotas, abril de 1982; Comendador do Governo do Distrito Federal, abril de 1982; Medalha do Mérito Agrícola: Confederação Nacional da Agricultura (CNA), 14 de dezembro de 1982; reconhecimento do Governo Francês, 2 de dezembro de 1982; Ordem do Rio Branco da Fundação Rio Branco, Grau Comendador, abril de 1983; Comendador do Tribunal Superior do Trabalho, 11 de agosto de 1984; Doctor Honoris Causa pela Purdue University (a distinção mais importante daquela universidade), Indiana, Lafayette, maio, 1985; Distinguished International Alumnus: Centennial Celebration of the Land Universities by the National Association of the State Universities and Land Grant Colleges (NASULGC), 1987; Prêmio Frederico de Menezes Veiga (distinção máxima da EMBRAPA, como reconhecimento a trabalhos de pesquisa), 26 de abril de 1988; Medalha do Ex-aluno da Universidade Federal de Viçosa, dezembro de 1990; Medalha Secundino São José, 1997; Comendador da Ordem Nacional do Mérito Científico pela Presidência da República, Ministério de Ciência e Tecnologia, 1996; Prêmio Moinho Santista, 2000 (um dos mais prestigiosos prêmios do Brasil); Medalha Apolônio Sales, do Ministério da Agricultura, 23 de outubro de 2003. 


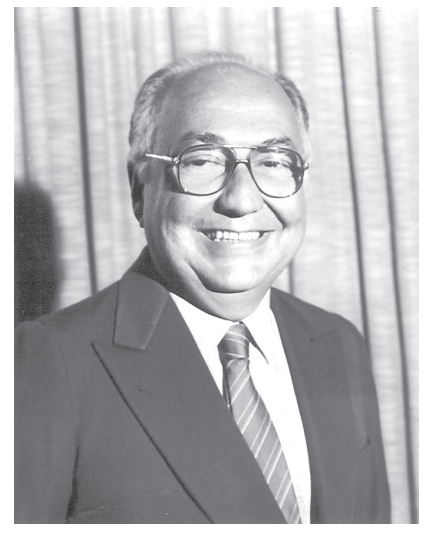

Paulo Fernando Cidade de Araújo
Nasceu em Porto Velho no Amazonas em 1932. Em 1956, engenheiro agrônomo pela Escola Nacional de Agronomia da Universidade Rural do Brasil, no Rio de Janeiro. Em 1964, economista pela Faculdade de Ciências Econômicas do Rio de Janeiro / SUESC. Nesse mesmo ano, docente contratado pela Universidade de São Paulo, na ESALQ em Piracicaba, depois de trabalhar alguns anos em assistência técnica no Ministério da Agricultura, Serviço Social Rural e Banco da Lavoura de Minas Gerais (hoje Banco Real) no Rio de Janeiro e depois, em Campinas, na Secretaria da Agricultura de São Paulo.

Em 1967, obteve o Master of Science em Economia Agrícola pela The Ohio State University, em Columbus - Ohio, nos Estados Unidos da América. Em 1969, doutor em Agronomia pela Escola Superior de Agricultura Luiz de Queiroz da USP na área de economia agrícola. Em 1983, por concurso público, chegou a professor titular, depois de passar pelos concursos de livre docência e professor adjunto. Lecionou desenvolvimento econômico, crédito rural, política agrícola e teoria econômica na ESALQ até 2001. A partir daí, professor visitante na Faculdade de Ciências Econômicas da Universidade do Estado do Rio de Janeiro, onde ensina e pesquisa até hoje.

Desempenhou funções técnicas e administrativas em São Paulo: - diretor geral do Instituto de Economia Agrícola da Secretaria da Agricultura de 1972 a 1977; - diretor do Centro de Estudos de Fertilizantes e coordenador de agroindústria no Instituto de Pesquisa Tecnológica; - diretor do Departamento de Ciência e Tecnologia, da Secretaria de Indústria e Comércio, Ciência e Tecnolo- 
gia; e - diretor presidente da Companhia de Promoção de Ciência e Tecnologia em sucessivos momentos do período 1977-1981.

Um dos idealizadores da Fundação de Estudos Agrários Luiz de Queiroz em 1976 e seu primeiro presidente até 1992. No final dos anos 80, prefeito do campus da USP em Piracicaba.

Em Brasília, integrou e presidiu a comissão de especialistas de ciências agrárias, no Ministério da Educação. No âmbito do MERCOSUL, consultor da Comissão dos Cursos de Agronomia. E até 2001, membro da comissão do exame nacional dos cursos de agronomia (provão).

Há vários anos vem exercendo, ad honorem, as funções de diretor administrativo e financeiro da Fundação Museu de Tecnologia de São Paulo.

No exterior: - visiting scholar of rural credit na The Ohio State University em 1977; - professor de desenvolvimento e política agrícola no Centro de Economia Agrária da Fundação Calouste Gulbenkian em Portugal, em 1982 e em 1984; - vice-president for administration da International Association of Agricultural Economists até 1985; - consultor e coordenador técnico do projeto rural finance em Moçambique, África, a serviço da FAO em 1992; e, - professor de mercados financeiros rurais na pós-graduação da Universidade Nova de Lisboa, Portugal, em 1993.

$\mathrm{Na}$ academia, orientou dezenas de estudantes de mestrado e doutorado em economia agrícola e aplicada e outros tantos em cursos de agronomia e economia. Publicou trinta artigos em periódicos com arbitragem, co-editou cinco livros sobre desenvolvimento da agricultura e escreveu onze capítulos de livros. Participou de setenta estudos técnicos e projetos de pesquisa. Como pesquisador, tem valorizado o estudo das relações econômicas entre os mercados de fatores e de produtos; com particular interesse nos efeitos da política de crédito nos países em desenvolvimento.

Como professor, recebeu distinções e honrarias de grande valor. Dentre elas: - Distinguished alumni award, Agricultural College, The Ohio State University, 1986; - Special Honoree, The Ohio State University on the occasion of its 300th commencement, 1987; - Troféu do centenário da ESALQ, 2001; - Paraninfo da 1a turma de economistas da ESALQ , 2001; e, por decisão espontânea dos estudantes de economia da ESALQ, em 2003 seu nome foi atribuído ao centro acadêmico - Centro Acadêmico Paulo Cidade (CAPC). Presidiu a SOBER de 1991 a 1993. 